\title{
PERFIL EPIDEMIOLÓGICO HIV/AIDS NO ESTADO DO PIAUÍ EM 2019
}

\section{Epidemiological Profile HIV/AIDS In The Piaui State In 2019}

\section{Perfil Epidemiológico VIH/SIDA En El Estado Piauí En 2019}

“Artigo premiado no V Congresso Internacional de Atenção Primária à Saúde-V CIAPS, realizado em Teresina-PI, em 2021"

Ivanildo Gonçalves Costa Júnior - Estudante do curso de Bacharelado em Enfermagem pela Universidade Federal do Piauí • Campus Senador Helvídio Nunes de Barros - UFPI/CSHNB • E-mail: juniorcosta1000jc@gmail.com

Sara Joana Serra Ribeiro - Estudante do curso de Bacharelado em Enfermagem pela Universidade Federal do Piauí - Campus Senador Helvídio Nunes de Barros UFPI/CSHNB・E-mail: joanasara98@gmail.com

João Matheus Ferreira do Nascimento - Estudante do curso de Bacharelado em Enfermagem pela Universidade Federal do Piauí • Campus Senador Helvídio Nunes de Barros - UFPI/CSHNB • E-mail: matheus_fn12@hotmail.com

Tiago Soares • Estudante do curso de Bacharelado em Nutrição pela Universidade Federal do Piauí • Campus Senador Helvídio Nunes de Barros - UFPI/CSHNB • E-mail: tyagosoares3@gmail.com

Denival Nascimento Vieira Júnior • Enfermeiro • Aluno de Mestrado do Programa de Pós-Graduação em Biologia de Sistemas • Instituto de Ciências Biomédicas da Universidade de São Paulo - ICB-III/USP • E-mail: denivaljunior@usp.br

Autor correspondente:

Ivanildo Gonçalves Costa Júnior • E-mail: juniorcosta1000jc@gmail.com 


\section{RESUMO}

Introdução: O vírus da imunodeficiência Humana e a Síndrome da Imunodeficiência Adquirida (HIV/Aids) ainda é expressivamente presente em grupos que sofrem de vulnerabilidades sociais, sendo um desafio ainda não superado, principalmente no que diz respeito ao desempenho de ações de saúde e por parte dos gestores no sentido da realização de prevenções amplas, baseadas nos contextos epidemiológicos das comunidades, cabendo também considerar os problemas de estrutura da rede de saúde para com o manejo diagnóstico, contextos de desigualdade e gênero que são as principais influencias para o desenvolvimento da doença. Objetivo: observar por meio de indicadores o panorama da situação do HIV/Aids no Piauí no ano de 2019. Metodologia: Estudo epidemiológico realizado através da plataforma do Departamento de informática do Sistema Único de Saúde. Foram consultados dados referentes ao período de 2019 do Estado do Piauí. Utilizou-se os indicadores de incidência, sexo, raça/cor, faixa etária, escolaridade e exposição, com foco nas taxas de incidência, óbitos e letalidade. Os dados foram agrupados e tabulados por meio dos programas Excel e Tabwin, utilizando o método de análise a técnica de percentagem. Resultados: No período vigente, o Estado apresentou 207 novos casos. A incidência foi de 6,32/100.000 habitantes, tendo maior detecção para o público masculino (73,91\%), faixa etária de 30-39 anos, maior predominância da população parda, escolaridade de ensino médio completo e heterossexuais. Quanto a mortalidade, foram notificados 134 óbitos por HIV, predominante para o sexo masculino. A Letalidade mostrou que $65 \%$ foram realmente afetadas pela doença. Conclusões: $\mathrm{O}$ perfil epidemiológico dos casos de $\mathrm{HIV} /$ Aids no Piauí foi caracterizado pela prevalência em determinados grupos, demonstrando que apesar da existência de políticas públicas que buscam a prevenção da doença, essa realidade ainda é presente nos dias atuais. Ressalta-se a importância da realização de estudos epidemiológicos para comparação e analise situacionais futuras.

Palavras-Chave: Epidemiologia. HIV. Perfil de Impacto da Doença.

\section{ABSTRACT}

Introduction: The Human Immunodeficiency Virus and the Acquired Immunodeficiency Syndrome (HIV/Aids) is still significantly present in groups that suffer from social vulnerabilities, being a challenge that has not yet been overcome, especially with regard to the performance of health actions and by the managers in the sense of carrying out comprehensive prevention, based on the epidemiological contexts of the communities, and it is also necessary to consider the problems of the structure of the health network in terms of diagnostic management, contexts of inequality and gender, which are the main influences on the development of the disease. Objective: observe through indicators the panorama of the situation of HIV/Aids in Piauí in the year 2019. Methodology: Epidemiological study carried out hrough the platform of the Information Technology Department of the Unified Health ystem. Data for the period 2019 in the State of Piauí were consulted. Indicators of cidence, sex, race/color, age, education and exposure were used, focusing on dence rates, deaths and lethality. Data were grouped and tabulated using Excel 
and Tabwin programs, using the method of analysis and the percentage technique. Results: In the current period, the State presented 207 new cases. The incidence was $6.32 / 100,000$ inhabitants, with greater detection for the male population $(73.91 \%)$, age group 30-39 years, greater predominance of the brown population, complete high school education and heterosexuals. As for mortality, 134 deaths from HIV were reported, predominantly for males. Lethality showed that $65 \%$ were actually affected by the disease. Conclusions: The epidemiological profile of HIV/Aids cases in Piauí was characterized by the prevalence in certain groups, demonstrating that despite the existence of public policies that seek to prevent the disease, this reality is still present today. The importance of conducting epidemiological studies for future situational comparison and analysis is highlighted.

Keywords: Epidemiology. HIV. Sickness Impact Profile.

\section{RESUMEN}

Introducción: El Virus de la Inmunodeficiencia Humana el Síndrome de Inmunodeficiencia Adquirida (VIH/Sida) sigue estando presente de manera significativa en grupos que padecen vulnerabilidades sociales, siendo un desafío aún no superado, especialmente en lo que respecta al desempeño de las acciones de salud y por el gestores en el sentido de realizar una prevención integral, con base en los contextos epidemiológicos de las comunidades, y también es necesario considerar los problemas de la estructura de la red de salud en términos de gestión diagnóstica, contextos de desigualdad y género, que son los principales influencias en desarrollo de enfermedad. Objetivo: observar indicadores a través del panorama de situación del VIH/Sida en Piauí en el año 2019. Metodología: Estudio epidemiológico realizado a través de la plataforma del Departamento de Tecnología de la Información del Sistema Único de Salud. Se consultó la fecha para el período 2019 en Estado de Piauí. Se utilizaron indicadores de incidencia, sexo, raza/color, edad, educación y exposición, centrándose en las tasas de incidencia, las muertes y letalidad. Los datos se agruparon, tabularon mediante programas Excel y Tabwin, utilizando método de análisis y técnica de porcentaje. Resultados: En período actual, el Estado presentó 207 nuevos casos. La incidencia fue de 6,32/100.000 habitantes, con mayor detección para población masculina (73,91\%), grupo etario 30-39 años, mayor predominio de la población morena, bachillerato completo y heterosexuales. En cuanto la mortalidad, se reportaron 134 muertes por $\mathrm{VIH}$, predominantemente por males. La letalidad mostró que el $65 \%$ estaba realmente afectado por enfermedad. Conclusiones: El perfil epidemiológico de los casos de VIH/Sida en Piauí se caracterizó por prevalencia de ciertos grupos, demostrando que a pesar de la existencia de políticas públicas que buscan prevenir la enfermedad, esta realidad sigue presente en actualidad. Se destaca importancia de realizar estudios epidemiológicos para futuros análisis y comparaciones situacionales.

labras clave: Epidemiología. VIH. Perfil de Impacto de Enfermedad. 


\section{Introdução}

O vírus da Imunodeficiência Humana/Síndrome da Imunodeficiência Adquirida (HIV/ Aids), conforme Villela e Barbosa ${ }^{1}$, ainda é expressivamente presente nos grupos de maiores vulnerabilidades sociais, com baixos níveis de escolaridade, precária inserção no mercado de trabalho, presença de violência na vida, demonstrando as diversas desigualdades sociais e de gênero, como sendo um desafio ainda não superado. Nesse sentido, ofertar ações de prevenção e diagnóstico que não se restrinjam a profissionais do sexo e gestantes, por exemplo, contribui no enfrentamento dessa pandemia, não negligenciando, contudo, as populações que são prioritárias pelo auto índice de incidência.

Conforme Gomes et al. ${ }^{2}$, a população de Homens que fazem Sexo com Homens (HSH) demonstrou que no Brasil os conhecimentos acerca das formas de transmissão da infecção pelo HIV são classificados como médio, ou baixo nível. O que se torna preocupante quando se considera a quantidade de informações básicas amplamente divulgadas. Tendo como agravante a desigualdade social no país evidenciada como forte indicador que contribui negativamente na epidemia e que, consequentemente, provoca uma maior disseminação da infecção pelo vírus. Configurando-se como um desafio para a área da saúde e gestores, principalmente, em desempenhar ações que busquem mudanças de ações preventivas amplas baseadas nos contextos epidemiológicos das diversas comunidades, sendo os elementos dos fatores de vulnerabilidades essenciais para desempenhar intervenções de nível estrutural, contribuindo para melhoria do conhecimento acerca do tema e consequentemente impactando positivamente na vida da população.

Os fatores sociodemográficos, de acordo com Miranda et al. ${ }^{3}$, além da não aceitação da doença, nível socioeconômico do indivíduo, baixa escolaridade, preconceito e ser do sexo masculino são questões fortemente associadas ao abandono tratamento, decréscimo da qualidade de vida e, posteriormente a morte daqueles e além de viver com HIV, possuem uma coinfecção como a tuberculose, por emplo. 
Em contraponto, a adesão do tratamento antirretroviral de pessoas que vivem com HIV/Aids em Ribeirão Preto - SP foi associada significativamente a maior faixa etária, maior tempo de diagnóstico, maior índice de escolaridade, menor quantidade de carga viral e maior quantidade de células Linfócitos do Grupamento de Diferenciação 4 (TCD4). Cabendo aos profissionais, através de abordagens multidisciplinares, integrais e multidimensionais promover, além do tratamento medicamentoso, o desenvolvimento de estratégias que busquem sempre a melhoria dos cuidados voltados para esse público ${ }^{4}$.

A pandemia causada pela COVID-19 acarreta diversos impactos, como analisa Jewel et al. ${ }^{5}$, nos estudos voltados para avaliação do potencial impacto sobre os programas de HIV na África Subsaariana, estimando-se um aumento excessivo de mortes por HIV durante esse período, que seriam provocadas, principalmente, pela interrupção do fornecimento dos antirretrovirais, mas também, pela suspensão de testes e ainda devido relutância das pessoas em buscar os cuidados por conta da exposição ao vírus Sars-CoV-2, sendo cotada a provável interrupção do fornecimento de preservativos, Profilaxia Pré Exposição (PrEP) entre outras medidas que tornam essa população ainda mais vulnerável. Estimou também que haveria um aumento expressivo do HIV, embora haja as medidas de distanciamento físico preconizadas. Com isso, podendo apagar rapidamente anos de ganhos de saúde pública se medidas substanciais não forem tomadas.

Paralelo a isso, os estudos de Rodger et al. ${ }^{6}$, evidenciaram através da observação de casais sorodiferentes heterossexuais e $\mathrm{HSH}$, nos quais o parceiro soropositivo estava usando terapia antirretroviral supressiva durante o tempo médio de 1,3 anos e tendo relação sexual sem preservativo que não houve casos de transmissão do HIV em casal. Houveram taxas mais baixas de transmissão do vírus entre casais heterossexuais, entre homens que fazem sexo com homens quando a pessoa está recebendo o tratamento antirretroviral. O início precoce desta terapia pode preservar função imunológica e reduzir as complicações relacionadas pela infecção pelo HIV, h-se observado também até que ponto o fornecimento da terapia precoce na redução incidência da infecção viral7. 
As reflexões trazidas por Monteiro et al. ${ }^{8}$, apontam para um novo olhar acerca dos papéis que devem ser desempenhados, mas que muitas vezes acabam caindo na lógica biomédica e tecnocrata de intervenções, ao contrário do que se quer e espera, gerando barreiras de acesso para diagnóstico e tratamento e estímulo a práticas de sexo seguro. Aponta que é preciso questionar os limites e os problemas desse tipo de lógica, discutindo as distorções, equívocos e lacunas existentes. Como se pode citar, por exemplo, a problematização do termo 'populações-chave' em detrimento de grupos vulneráveis ao HIV, ou ainda, grupo de risco, que remetem para efeitos negativos da associação do vírus a grupos marginalizados socialmente. Cabendo também, considerar os problemas de estrutura da rede de saúde no que se refere ao manejo de casos diagnosticados, contextos de desigualdades sociais e de gênero que tem forte influência para com isso, poder atuar da melhor forma possível.

As políticas dirigidas a HIV/Aids na Atenção Primaria à Saúde recentemente, no Brasil, se aproximam, primordialmente pela incorporação da testagem e diagnóstico do HIV (com foco maior em grávidas) e, posteriormente, através de diretrizes e experiências a nível de município de descentralização do cuidado a pessoas na atenção primária, que sem dúvidas é uma novidade social na saúde que precisa ser discutida, mas que apesar dos eminentes desafios se configura como uma oportunidade positiva que amplia as possibilidades de acesso e qualidade no cuidado das pessoas que vivem com HIV/Aids9.

O presente estudo objetiva observar por meio de indicadores o panorama acerca da situação HIV / Aids no estado do Piauí no ano de 2019.

\section{Metodologia}

\section{Local de estudo e população avaliada}

O local de estudo foi delimitado para o território pertencente ao Estado do Piauí, no qual fica localizado na região Nordeste do Brasil, tendo a cidade de Teresina como capital. Segundo os dados do Instituto Brasileiro de Geografia e Estatística $(B G E)^{10}$ a área territorial é de $251.756,515$ km². 
O Estado é composto por 224 municípios, a estimativa populacional do ano de 2020 era de 3.281.480 habitantes e índice de desenvolvimento humano (IDH) de 0,646 (dado referente a 2010). O território é dividido em quatro Macrorregiões de saúde: Meio-Norte, Litoral, Semiárido e Cerrados, e doze microrregiões.

\section{Indicadores}

As variáveis de estudo utilizadas tiveram como foco as taxas de casos novos (incidência), taxa de mortalidade (número de óbitos) e letalidade (capacidade de letal da doença) no Estado do Piauí no ano de 2019, associados aos seguintes indicadores:

- Incidência: A incidência diz respeito à velocidade a qual os novos eventos ocorrem em determinada população. Esta é utilizada para expressar o risco de tornar-se doente, tida como uma das principais medidas para doenças e condições agudas, o que não impede que seja usada para doenças crônicas ${ }^{11}$.

- Sexo: Feminino e masculino;

- Raça/cor: Branca, preta, parda, amarela e indígena;

- Faixa etária: 1 a 14 anos, 15 a 19, 20 a 29, 30 a 39, 40 a 49, 50 a 59, 60 a 69, e $70 \geq$ anos.

- Escolaridade: Analfabeto, $1^{\mathrm{a}}$ a $4^{\mathrm{a}}$ série, $4^{\mathrm{a}}$ série completa, $5^{\mathrm{a}}$ a $8^{\mathrm{a}}$ série incompleta, fundamental completo, médio incompleto, médio completo, superior incompleto e superior completo.

- Categoria de exposição agrega os grupos: Homossexual, bissexual, heterossexual, Uso de Drogas Injetáveis (UDI) e transmissão vertical.

\section{Mortalidade}

As medidas de mortalidade visam sugerir ações que reduzam o risco de morrer por causas evitáveis, ao passo que indicam a necessidade de ações de controle sobre os fatores de risco de adoecer ou sofrer agravos que se associam à alta letalidade ${ }^{12}$.

- Coeficiente de Mortalidade Geral: É calculada dividindo -se o número total de óbitos naquele ano pela população total daquele ano e multiplicado pela constante 10n. Este coeficiente possui importância significativa no estudo das 
condições sanitárias de determinada população quando comparada a outros coeficientes, índices e taxas ${ }^{12}$.

- Coeficiente de Mortalidade Específica: O objetivo principal é calcular o risco de mortalidade de determinada doença para uma fração da população.

- Coeficiente de Mortalidade Específica/causa: Número de óbitos por uma causa específica expresso por 100.000 habitantes em determinado local e período.

- Coeficiente de Mortalidade Específica/sexo: Número de óbitos por causa específica detalhada de acordo com o sexo expresso por 100.000 habitantes em determinado local e período.

\section{Letalidade:}

A letalidade mede o nível de severidade de uma determinada doença e definese como a proporção de mortes dentre aqueles doentes por uma causa específica em um certo período de tempo. Para calcular o índice de letalidade divide-se o número de óbitos por determinada causa pelo número de indivíduos atingidos pela doença e multiplica-se o resultado por $100{ }^{11}$.

Fontes de dados e softwares utilizados:

As fontes utilizadas para levantamento de dados referente às informações foram: Departamento de informática do Sistema Único de Saúde (DATASUS), IBGE, Sistema de Informação de Agravos de Notificação (SINAN). Os dados coletados foram tabulados, analisados e dispostos em tabelas com o auxílio dos programas Excel software Microsoft Office 2010 e Tabwin versão 4.1.5. Como método de análise, utilizou-se a análise estatística descritiva empregando-se a técnica de percentagem.

Por se tratar de uma pesquisa realizada com base em dados secundários, de livre acesso nos meios eletrônicos, contida em bancos de dados de domínio público, este trabalho não necessitou de apreciação em Comitê de Ética em Pesquisa (CEP), estando de acordo com a Resolução 466/12 do Conselho Nacional de Saúde ${ }^{13}$. 


\section{Resultados e Discussão}

\section{Incidência}

Em 2019 o Piauí apresentou 207 novos casos de HIV/Aids, a incidência referente ao ano todo foi de 6,32 novos casos/100.000 habitantes. A detecção de novos casos foi de maior incidência para o público masculino onde totalizou 153 notificações correspondendo a 73,91\% dos casos. De acordo com Araújo ${ }^{14}$ em comparação ao parâmetro nacional, o sexo masculino sobrepôs o feminino nas categorias homossexuais, bissexuais, UDI e nos casos ignorados, enquanto o feminino, superou os percentuais na categoria heterossexual.

No que se refere a idade, o grupo de pessoas na faixa etária de 30-39 anos apresenta a maior incidência, seguida da população entre 40-49 anos. Em contrapartida, a faixa etária entre 15-19 anos possui o menor número de casos (Gráfico 1). A sabedoria de que os sintomas da Aids aparecem tardiamente pode ser apontado como elemento da vulnerabilidade dos adolescentes ao HIV, a adoção do comportamento preventivo seria mais provável se as manifestações do agravo fossem imediatas. Uma vez que a Aids não é percebida de forma imediata à relação sexual desprotegida, os adolescentes passam a considerá-la uma ameaça distante de seu cotidiano deixando a prevenção em segundo plano ${ }^{15}$.

Gráfico 01 - Casos de HIV/Aids por faixa etária e sexo. Picos - Piauí, 2021.

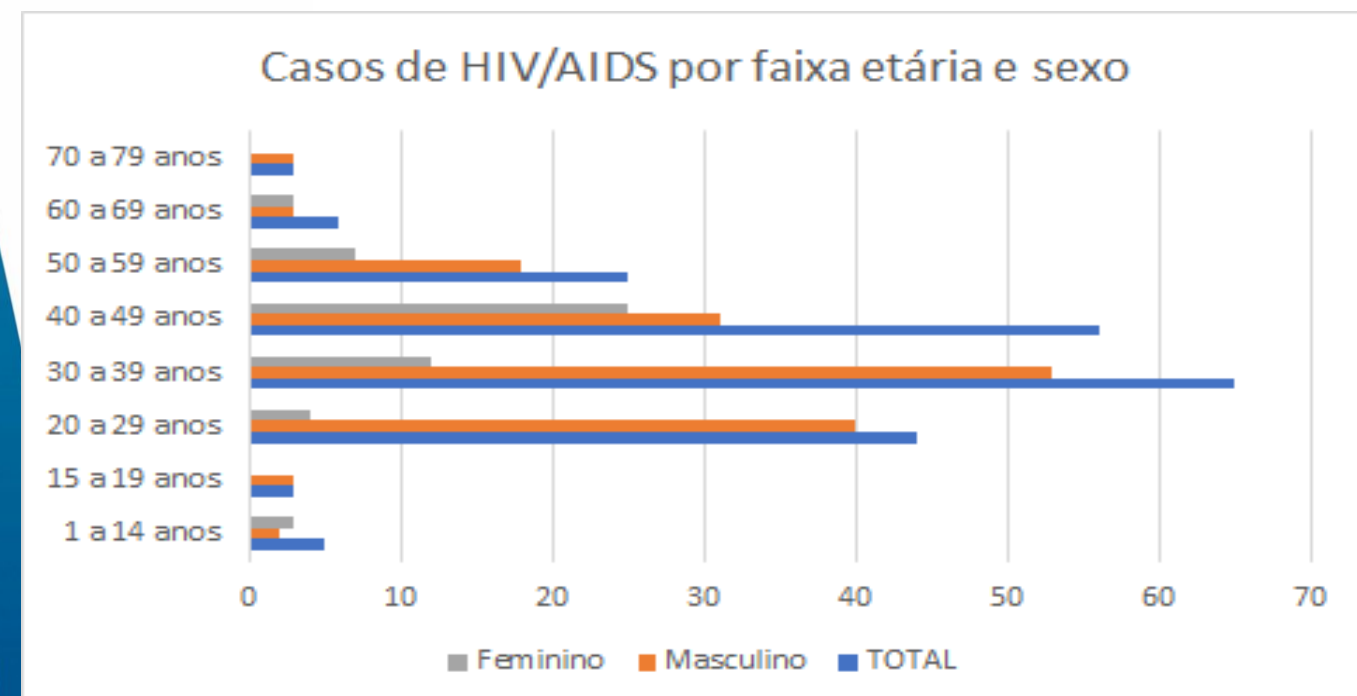

te: Autores, 2021. [Dados extraídos do DATASUS16]. 


\section{ciência plural}

Sobre o indicador raça/cor, a população de identificação parda tem predominância do número de positivação com o total de 138 no que diz respeito ao ano de 2019 (Gráfico 2). O público masculino que se autodeclara de cor parda também domina o índice com 102 casos. Em contrapartida, homens indígenas e amarelos apresentam a menor numerador de contaminação com 1 e 2, respectivamente. Já o público feminino de cor/raça amarela e indígena não obtiveram casos no referido ano.

Gráfico 02 - Casos de HIV/Aids por raça/cor. Picos - Piauí, 2021.

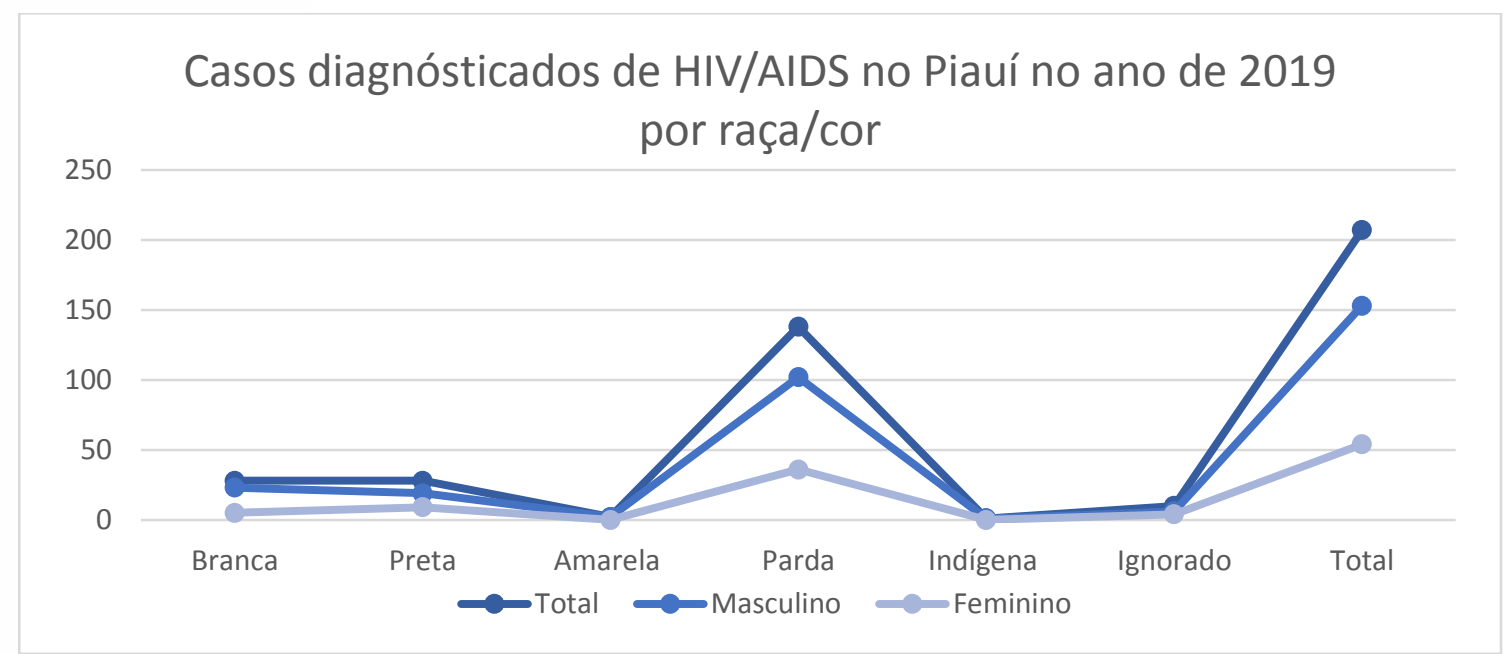

Fonte: Autores, 2021. [Dados extraídos do DATASUS16].

Em relação a escolaridade, parte significativa de pessoas com diagnóstico de HIV / Aids fizeram o ensino médio completo (Gráfico 3), chama atenção para a baixa taxa de infecção em analfabetos com apenas 12 o que pode ser explicado pela dificuldade de acesso ao exame bem como pela falta de informação. 
Gráfico 03 - Escolaridade dos indivíduos diagnosticados com HIV/Aids. Picos - Piauí, 2021.

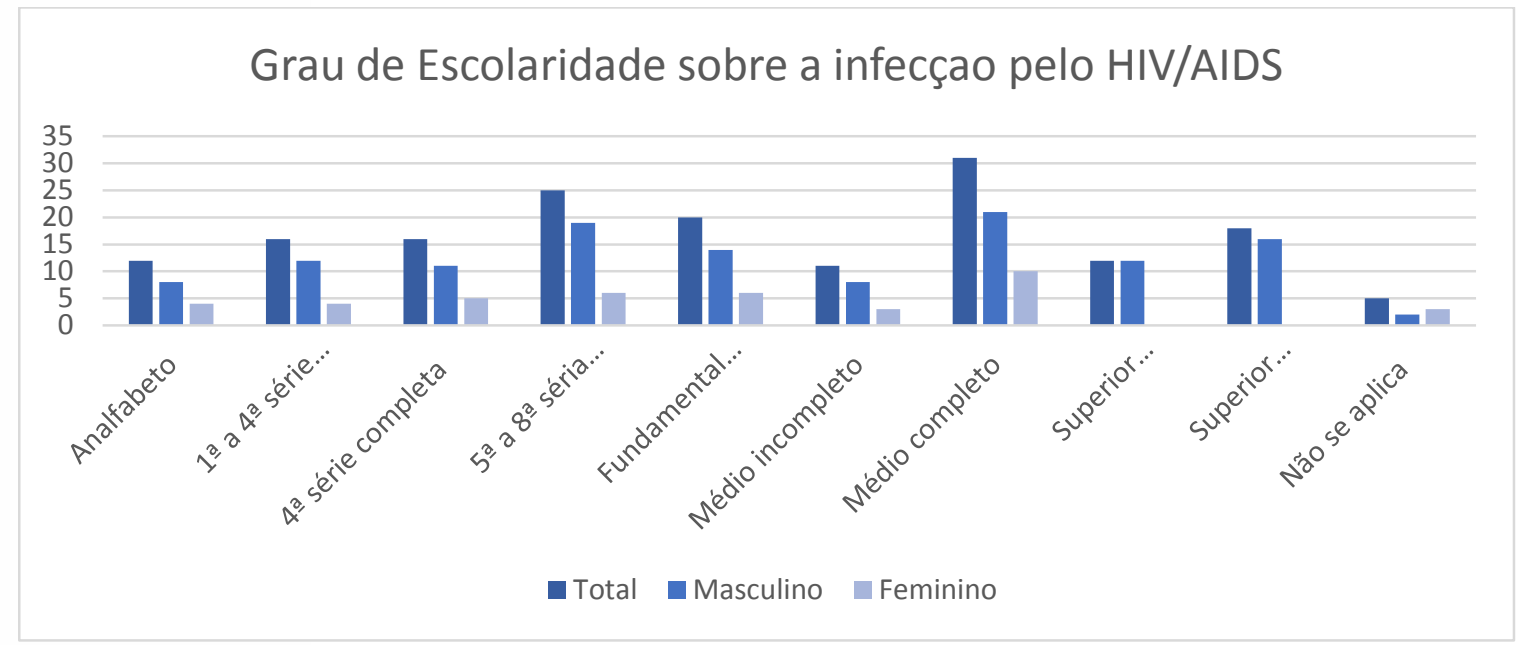

Fonte: Autores, 2021. [Dados extraídos do DATASUS16].

Diante dos dados obtidos de categoria agregada a grupos (heterossexuais, bissexuais, homossexuais e ignorados), os números são bem mais relevantes quando comparamos a quantidade de Heterossexuais (97) com os demais grupos, contrariando o estigma de que a população do HIV/Aids estaria concentrada na população a qual os grupos são marginalizados socialmente, tais quais homossexuais (48), bissexuais (24), por exemplo. Uma ressalva para que as políticas de saúde trabalhem com populações chaves de modo a garantir que estas sejam realmente atingidas ${ }^{17}$.

De acordo com Piauiense ${ }^{18}$, dentre os piores indicadores para HIV/Aids encontra-se a região nordeste, cenário este que vem sofrendo mudanças nos seu perfil epidemiológico marcada por processos tais quais: pauperização, envelhecimento, juvenização, heterossexualização, feminização e interiorização, evidenciando que não são apenas determinados grupos, os quais podem ser considerados vulneráveis ao HIV, ao passo que desmistifica a relação do vírus com a homossexualidade, promiscuidade e outros estigmas que permeiam a doença.

Mortalidade

Segundo o DATASUS, o estado do Piauí no ano de 2019, notificou 20.500 óbitos, rando o coeficiente geral de mortalidade de 626,29 mortos por 100.000 habitantes. ste mesmo ano, foram registrados 134 óbitos tendo o HIV como causa, o que 
representa 4,08 óbitos por HIV a cada 100.000 habitantes. Ao passo que, 3,08 óbitos por HIV são do sexo masculino para 01 óbito do sexo feminino, informações indicadas na Tabela 01, a seguir:

Tabela 01 - Coeficiente de Mortalidade Específica segundo o sexo. Picos - Piauí, 2021.

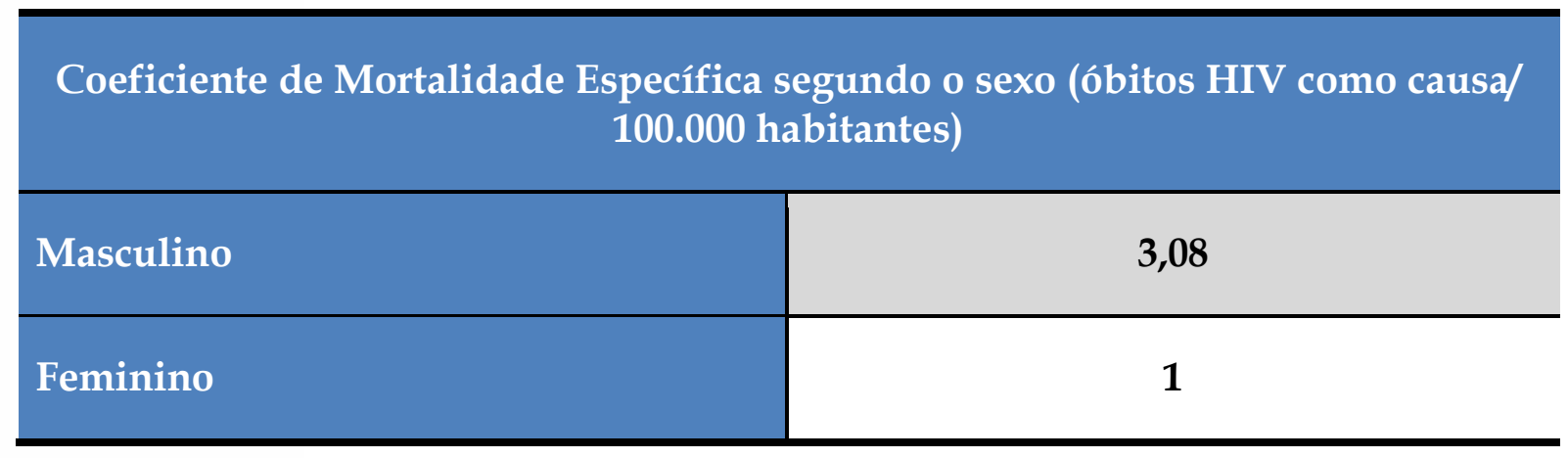

Fonte: Autores, 2021. [Dados extraídos do DATASUS16].

Ademais, questiona-se: o que pode ser melhorado nas ações voltadas para HIV/Aids? Os números disponíveis nos sistemas de informação condizem com a realidade? E quanto aos indivíduos que não procuram os serviços de saúde? As políticas públicas cumprem os seus objetivos? No contexto da pandemia da Covid-19, será que estes números serão ou são fidedignos? A partir das informações depreendese que apesar dos avanços no que tange ao combate a HIV/Aids, este ainda é um problema de saúde pública que demanda muitos esforços, seja na aproximação do homem nos serviços de saúde, na facilitação do acesso à informação nos diferentes contextos socioeconômicos, políticos e culturais, ou na desconstrução de estigmas, mitos e preconceitos que envolvem o indivíduo soropositivo ${ }^{8}$.

A carga viral elevada, baixa dosagem de linfócito CD4, comorbidades e má adesão ao tratamento, são fatores os quais contribuem para a má evolução de uma infecção por HIV. Apesar de no Brasil, o acesso às medicações acontecer de forma universal e gratuita, menos da metade dos infectados fazem uso destas de forma regular, fator este que ainda, não afetou diretamente as taxas de mortalidade, tendo em vista que os números apresentam decréscimo. No entanto, a nível regional e a espeito da aplicação de programas e políticas de saúde, algumas regiões do país os lores de mortalidade são altos quando comparados aos índices nacionais ${ }^{19}$. 


\section{Letalidade}

Dados do último Boletim Epidemiológico de HIV / Aids do Ministério da Saúde, publicado em 27 de novembro de 2019, apontam que, de 1980 a junho de 2019, cerca de 966 mil casos de HIV/Aids já foram detectados, com 338,9 mil óbitos no mesmo período. Onde só no estado do Piauí foram registrados 134 óbitos. Constata-se também que 207 pessoas foram realmente afetadas pela doença. Conforme o cálculo para identificar a letalidade da doença - Cálculo: (134 óbitos / 207) x 100 =65\% de letalidade (Gráfico 04).

Gráfico 04 - Letalidade do HIV/Aids no Piauí no ano de 2019. Picos - Piauí, 2021.

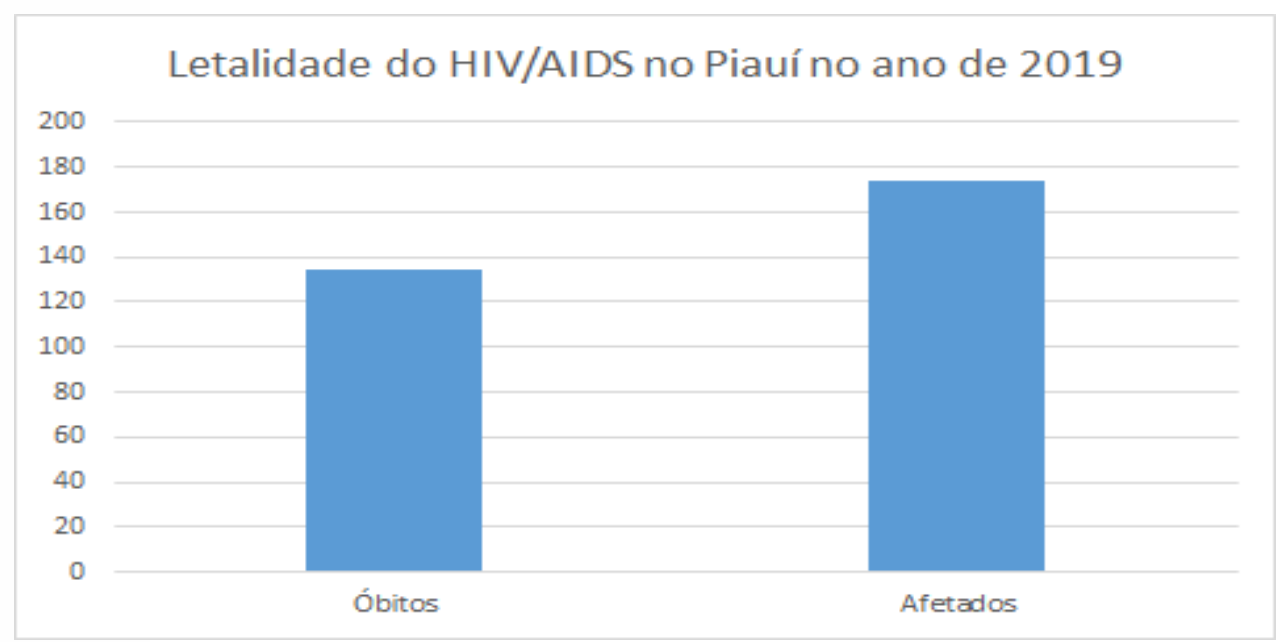

Fonte: Autores, 2021. [Dados extraídos do DATASUS16].

A partir da disponibilização da terapia com o uso de antirretrovirais, a expectativa de vida dessas pessoas aumentou consideravelmente, logo é extremamente necessário conhecer os fatores sociais que contribuem para o adoecimento por causas relacionadas à Aids, considerando, a heterogeneidade da epidemia HIV/Aids nas diferentes regiões do Brasil, o que exige abordagens diferentes de acordo com cada especificidade, de modo a fortalecer as políticas de saúde que beneficie a sociedade em seus diferentes segmentos sociais ${ }^{20}$.

\section{Tonclusões}

O perfil epidemiológico dos casos de Aids no Piauí no ano de 2019 apresentou cenário marcado pela prevalência de adultos jovens, do sexo masculino, com idade re 30 e 39 anos, de cor da pele parda, com ensino médio completo e que contraíram 
o vírus por meio de relações heterossexuais. Apesar de existirem políticas públicas e campanhas em alusão a prevenção e tratamento, HIV/Aids ainda é uma enfermidade que assola a população piauiense.

Vale ressaltar a importância do desenvolvimento de mais estudos epidemiológicos visando comparar e avaliação situações anteriores e assim possibilitar diagnósticos situacionais, bem como, o desenvolvimento e implementação de estratégias que visem a prevenção de novos casos da doença.

\section{Referências}

1. Villela WV, Barbosa RM. Trajetórias de mulheres vivendo com HIV/aids no Brasil. Avanços e permanências da resposta à epidemia. Ciência \& Saúde Coletiva. 2017; 22(1): 87-96.

2. Gomes RRFM, Ceccato MGB, Kerr LRFS, Guimarães MDC. Fatores associados ao baixo conhecimento sobre HIV/AIDS entre homens que fazem sexo com homens no Brasil. Cad. Saúde Pública [online]. 2017; 33(10): 1-15.

3. Miranda LO et al. Coinfecção Tuberculose/HIV no Brasil: revisão integrativa. Rev. Pre. Infec. e Saúde [online]. 2017; 3(3): 59-70.

4. Foresto JS, Melo ES, Costa CRB, Antonini M, Gir E, Reis RK. Adesão à terapêutica antirretroviral de pessoas vivendo com HIV/aids em um município do interior paulista. Rev. Gaúcha Enferm. [online]. 2017; 38(1): 1-7.

5. Jewell BL, et al. Potential effects of disruption to HIV programmes in sub-Saharan Africa caused by COVID-19: results from multiple mathematical for the HIV Modelling Consortium. Lancet HIV [online]. 2020; 7(1): 629-640.

6. Rodger AJ, et al. Sexual Activity Without Condoms and Risk of HIV Transmission in Serodifferent Couples When the HIV-Positive Partner Is Using Suppressive Antiretroviral Therapy. American Medical Association. 2016; 316(2): 171-181.

7. Cohen MS, et al. Antiretroviral Therapy for the Prevention of HIV-1 Transmission. The new england journal of medicine. 2016; 375(9): 830-839.

Monteiro SS, Brigeiro M, Vilella WV, Mora C, Parker R. Desafios do tratamento mo prevenção do Hiv no Brasil: uma análise a partir da literatura sobre testagem. iência \& Saúde Coletiva [online]. 2019; 24(5): 1793-1807. 
9. Melo EA, Maksud I, Agostini R. Cuidado, HIV/Aids e atenção primária no Brasil: desafio para a atenção no Sistema Único de Saúde? Rev. Panam. Salud. Publica[online]. 2018; 42(1): 1-5.

10. Instituto Brasileiro de Geografia e Estatística (IBGE). Diretoria de Pesquisas. Coordenação de População e Indicadores Sociais. Estimativas da População Residente com Data de Referência 1º de junho de 2019. Rio de Janeiro: IBGE; 2019.

11. Bonita R, Beaglehole R, Kjellström T. Medindo Saúde e Doença. In: R. Bonita R, Beaglehole T, Kjellstrom T. Epidemiologia Básica. São Paulo: Santos Editora. 2010, p. 15-38.

12. Mota E, Kerr LRFS. Medidas de ocorrência de doenças, agravos e óbitos. In: Almeida Filho N, Barreto ML. (Org.). Epidemiologia Saúde: fundamentos, métodos, aplicações. Rio de Janeiro: Guanabara Koogan. 2011; p. 95-117.

13. Brasil. Resolução $N^{\circ} 466$ de 12 de dezembro de 2012. Aprova as diretrizes e normas de pesquisa envolvendo seres humanos e revoga as Resoluções CNS nos. 196/96, 303/ 2000 e 404/2008. Diário Oficial da União. De dezembro de 2012. Disponível em: https://bvsms.saude.gov.br/bvs/saudelegis/cns/2013/res0466_12_12_2012.html

14. Araújo DAM, Vieira Júnior DN, Nascimento JMF, et al. Análise do perfil epidemiológico do número de casos de aids no Brasil nos últimos 10 anos. Saúde Coletiva (Barueri). 2021; 11(65), 6054-6065. Disponível em: http://www.revistas.mpmcomunicacao.com.br/index.php/saudecoletiva/article/vi ew/1590

15. Toledo MM, Takahashi RF, De-la-torre-ugarte-guanilo MC. Elementos de vulnerabilidade individual de adolescentes ao HIV/AIDS. Rev. bras. enferm. vol.64 n0.2 Brasília Mar./ Apr. 2011.

16. DATASUS. Sistema de Informação de Agravos de Notificação (SINAN). 2019. Disponível em: http:/ / www2.aids.gov.br/cgi/deftohtm.exe?tabnet/br.def

17. Escore M. O conceito de riscos das Políticas de HIV/Aids no contexto de transformações sociais contemporâneas. Dissertação - Faculdade de Saúde Pública da Universidade Federal de São Paulo, São Paulo, 2019.

18. Piauiense JNF. Epidemiologia da HIV/ AIDS em teresina-pi: análise retrospectiva. Brazilian Journal of Surgery and Clinical Research, v. 21, p. 07-12, 2018.

Matsubara ACS, Gavioli BM, Marcomini GS, Yassumoto GS, Rosa RS. Causas de prte em pessoas vivendo com HIV no município de Catanduva nos anos 2014 a 2018. id Enferm. 2020; 14(2): 138-146. 


\section{ciência
purála}

20. Maranhão TA, Sousa GJB, Alencar $\mathrm{CH}$, Magalhães MAFM, Abreu WC, Pereira MLD. Influência dos Determinantes Sociais sobre a incidência de AIDS no Piauí: um estudo ecológico. Texto Contexto Enferm [Online]. 2020; 29: 1-15. 